\title{
Screening of Antibacterial Compounds in Salvia officinalis $L$. Tincture Using Thin-Layer Chromatography-Direct Bioautography and Liquid Chromatography-Tandem Mass Spectrometry Techniques
}

\author{
Wioleta Jesionek, Barbara Majer-Dziedzic, Györgyi Horváth, Ágnes M. Móricz, and Irena M. Choma*
}

Key Words:

Salvia officinalis $\mathrm{L}$.

Thin-layer chromatography-direct bioautography

Antibacterial activity

Bioassay

Liquid chromatography-quadrupole time-of-flight mass spectrometry

\begin{abstract}
Summary
Thin-layer chromatography-direct bioautography (TLC-DB) followed by liquid chromatography-tandem mass spectrometry (LC-MS/MS) was used for screening and tentative identification of the antibacterial constituents of Salvia officinalis L. ethanol extract. Seven bacterial strains were used as test organisms, both pathogenic and nonpathogenic, that is, Staphylococcus aureus, methicillin-resistant S. aureus (MRSA), Staphylococcus epidermidis, Micrococcus luteus, Bacillus subtilis, luminescence gene-tagged Pseudomonas syringae pv. maculicola, and naturally luminescent marine bacterium Aliivibrio fischeri. Eight fractions with the widest antimicrobial spectrum were detected using TLC-DB, isolated by semi-preparative TLC, and subjected to LC-MS/MS analyses. Finally, five bioactive components were tentatively identified, based on their fragmentation pattern, such as salvigenin, cirsimaritin, rosmanol, carnosic acid, and 12- $O$-methyl carnosic acid.
\end{abstract}

\section{Introduction}

Salvia officinalis L., sage (also called garden sage, kitchen sage, or common sage), is a popular perennial plant belonging to the Lamiaceae family together with other aromatic plants like basil, mint, rosemary, oregano, marjoram, lavender, or thyme. Sage is native to the Mediterranean region although nowadays it is popular in many countries throughout the world. It has a very long tradition of culinary and medicinal use with a broad range of applications. S. officinalis L. has well-known anti-inflammatory, antibacterial, antifungal, and antioxidant properties [1, 2]. The essential oil (EO) is widely applied in aromatherapy and cosmetology. The composition and biological properties of

W. Jesionek and I.M. Choma, Department of Chromatographic Methods, M. Curie-Skłodowska University, M. Curie-Skłodowska Sq. 3, 20-031 Lublin, Poland; B. Majer-Dziedzic, Department of Veterinary Microbiology, University of Life Sciences, Akademicka St. 13, 20-950 Lublin, Poland; Gy. Horváth, Department of Pharmacognosy, Faculty of Pharmacy, University of Pécs, Rókus St. 2, 7624 Pécs, Hungary; and Á.M. Móricz, Plant Protection Institute, Centre for Agricultural Research, Hungarian Academy of Sciences, Herman Ottó St. 15, 1022 Budapest, Hungary.

E-mail: irena.choma@poczta.umcs.lublin.pl
S. officinalis (especially of the EO) are well described in the literature [1-3]. However, there is not enough information on relations between the biological properties and the chemical composition of the plant. One of the methods used in assessing the biological activities to plant constituents is hyphenation of thin-layer chromatography (TLC) with a biological assay (e.g., testing antimicrobial properties) performed directly on a chromatographic plate, i.e., thin-layer chromatography-direct bioautography (TLC-DB) [4-6]. In the case of testing biological properties, the developed TLC plate is immersed in bacterial suspension and left for incubation. Bacteria grow directly on the surface of the TLC plate except for the spots of antibacterial substances. Then, the plate is visualized by spraying with tetrazolium salt which is converted by bacteria into the purple formazan. When luminescent bacteria are used as test organisms, visualization is performed by the detection of light emission of viable cells with a low-light camera. TLC-DB followed by an identification of biological active substances (e.g., by spectroscopic methods) belongs to the effect-directed analyses (EDA) [7-10]. In the presented paper, TLC-DB of sage tincture against seven bacterial strains, both pathogenic and nonpathogenic, was performed to find the components with the widest range of antibacterial properties. The structural identification of the active fractions isolated from TLC plates was carried out using liquid chromatography-tandem mass spectrometry (LC-MS/MS).

\section{Experimental}

\subsection{Chemical Reagents}

The solvents for TLC of analytical grade, i.e., chloroform stabilized with amylene, diethyl ether, methanol, and ethanol, were purchased from POCh (Gliwice, Poland). Sulfuric and glacial acetic acid (POCh) were used for the preparation of anisaldehyde derivatization reagent. LC-MS-grade acetonitrile and methanol were acquired from Merck (Warsaw, Poland), while formic acid of analytical purity grade was purchased from Sigma-Aldrich (Poznań, Poland). 4-Methoxybenzaldehyde ( $p$-anisaldehyde) was from Merck (Hohenbrunn, Germany). Mueller-Hinton (M-H) broth, M-H agar, and agarose were 
purchased from Oxoid (Hempshire, UK). 3-(4,5-Dimethylthiazol-2-yl)-2,5-diphenyltetrazolium bromide (MTT), Hepes, and Triton X-100 were from Sigma-Aldrich (St. Louis, MO, USA).

\subsection{Materials and Equipment}

\subsubsection{Plant Material}

S. officinalis L. extract was prepared by a seven-day maceration of the herb with $70 \%$ ethanol. The drug extract ratio was $1: 3.3$, which means that $1 \mathrm{~kg}$ of sage herb was used to obtain $3.3 \mathrm{~kg}$ of the final extract. The plant extract was obtained from Herbapol-Lublin S.A., Lublin, Poland. The tincture was stored at $4^{\circ} \mathrm{C}$ to prevent degradation by light and temperature.

\subsubsection{Bacterial Strains}

TLC-DB was performed against the following bacterial strains: Micrococcus luteus (Ml; ATCC 9341), Bacillus subtilis (Bs; ATCC 6633), Staphylococcus aureus (Sa; ATCC 29213), methicillin-resistant $S$. aureus (MRSA), Staphylococcus epidermidis (Se); luminescence gene-tagged Pseudomonas syringae pv. maculicola (Pmlux, John Innes Center, Norwich, UK), and naturally luminescent marine bacterium Aliivibrio fischeri (Af, Lumistox test strain, Hach-Lange Ltd, Düsseldorf, Germany). S. epidermidis and MRSA were isolated from blood cultures.

\subsubsection{Thin-Layer Chromatography}

Both TLC analytical and semi-preparative separations as well as TLC-DB tests were performed on analytical $10 \times 20 \mathrm{~cm}$ aluminum-backed TLC Si60 $\mathrm{F}_{254}$ plates (Merck, Darmstadt, Germany). In the case of analytical separations, the plant ethanol extract was applied in $5-\mu \mathrm{L}$ volumes as $5-\mathrm{mm}$ bands, and the TLC plates were developed with the previously optimized mobile phase: chloroform-diethyl ether-methanol (30:10:1, $v / v)$ to a $8-\mathrm{cm}$ distance using a horizontal chamber (Chromdes, Lublin, Poland). All TLC separations were performed at room temperature $\left(21 \pm 1^{\circ} \mathrm{C}\right)$. After chromatographic separation, the adsorbent layers were dried at room temperature for $2 \mathrm{~h}$ to remove the mobile phase completely. The TLC plates used both for chemical derivatization and for bioautography were developed under the same conditions. TLC plates for bioautography were prepared without a derivatization step. Chemical derivatization was carried out with anisaldehydesulfuric acid reagent (AS) [11]. After spraying with AS, the plates were heated at $100^{\circ} \mathrm{C}$ for $5 \mathrm{~min}$. Initial identification of the separated compounds was performed on the basis of $R_{\mathrm{F}}$ values and colors of the compounds observed under UV light before and after derivatization. In the case of a semi-preparative separation, $150 \mu \mathrm{L}$ of the extract was applied as $15 \mathrm{~cm}$ band on an analytical TLC plate which was developed to $8 \mathrm{~cm}$ distance with the same mobile phase as used previously for analytical separations. The plates were documented using the TLC Visualizer (CAMAG, Muttenz, Switzerland).

\subsubsection{Direct Bioautography}

The antibacterial activity of the $S$. officinalis L. extract was investigated by TLC-DB toward the following reference bacterium: Ml, Bs, Sa, MRSA, Se, Pmlux, and Af. The developed TLC plates tested against Ml, Bs, Sa, MRSA, and Se were dipped in the proper bacterial cell suspension in Muller-Hinton broth $\left(1.2 \times 10^{7} \mathrm{CFU} \mathrm{mL}{ }^{-1}\right.$ for Bs; $1.2 \times 10^{8} \mathrm{CFU} \mathrm{mL}^{-1}$ for $\mathrm{Ml}$, Sa, $\mathrm{MRSA}$, and $\mathrm{Se}$ ) for $10 \mathrm{~s}$ and then placed into a moistened plastic box lined with a wetted paper at $37^{\circ} \mathrm{C}$. After 5 -h incubation, the plates were dipped in the aqueous solution of MTT $(0.05 \mathrm{~g} /$ $90 \mathrm{~mL}$ ) for $5 \mathrm{~s}$ and further incubated at $37^{\circ} \mathrm{C}$ for $2 \mathrm{~h}$. Visualization of the inhibition zones of the separated compounds was based on the dehydrogenase activity of the metabolically active bacteria. This enzyme system converts the yellow tetrazolium salt, MTT, into purple MTT-formazan. The creamy spots visible against a purple background, so-called inhibition zones, pointed to the presence of antimicrobial agents.

In the case of luminescent bacteria, Pmlux, and Af, the plates were dipped into the cell suspension $\left(3.6 \times 10^{8} \mathrm{CFU} \mathrm{mL}^{-1}\right.$ and $7.2 \times 10^{8} \mathrm{CFU} \mathrm{mL}^{-1}$ in bulion, respectively) and enclosed in a home-made glass cage $(20 \times 20 \times 1 \mathrm{~cm})$, ensuring transparency. The narrow cage protected against drying and provided sufficient air for respiratory activity which was required for cell proliferation taking place directly on the adsorbent layer. The bioautograms were documented immediately after immersion using a computer-controlled cooled charge coupled device camera (IS-4000, Alpha Innotech, San Leandro, CA). The exposure time was $15 \mathrm{~min}$ for Pmlux and $5 \mathrm{~min}$ for Af. The light emitted by the bacterial cells is closely dependent on the metabolic activity (which in turn depends on viability), so the darker areas on the images indicate the lack of metabolic activity.

\subsubsection{LC-MS/MS Analysis}

High-resolution mass spectrometry experiments were carried out using a liquid chromatograph (series 1200, Agilent Technologies) fitted with a nano pump, capillary pump, thermostat, and microautosampler coupled to a tandem mass spectrometer (Agilent Technologies 6538 UHD Accurate Mass Q-TOF LC-MS) equipped with an HPLC-chip cube. Instrument control and data acquisition were performed using an Agilent Mass Hunter Acquisition module (version B.04). Chromatographic separations were performed on a large capacity column Chip II $(160 \mathrm{~nL}, \mathrm{C} 18150 \times 0.075 \mathrm{~mm}, 5 \mu \mathrm{m})$ from Agilent Technologies (Perlan Technologies, Warsaw, Poland) using a nano pump. The analyses used a 9 -min linear gradient of aqueous $0.1 \%$ formic acid (A) and $0.1 \%$ formic acid in acetonitrile (B) increasing from 3 to $98 \%$ B, with a $1-$ min hold at $98 \%$ B and a 1.5 -min postrun at $3 \% \mathrm{~B}$. The mobile phase flow rate was $0.5 \mathrm{~mL} \mathrm{~min}^{-1}$. The capillary pump mobile phase flow rate was set at $4 \mathrm{~mL} \mathrm{~min}{ }^{-1}$. The analytes were ionized in the chip cube nano-electrospray in the positive ion polarity mode. The ion source gas (nitrogen) temperature was $350^{\circ} \mathrm{C}$, and the flow rate was $3.5 \mathrm{~L} \mathrm{~min}^{-1}$. The capillary potential was set at $-1750 \mathrm{~V}$, and the fragmentor was set at $100 \mathrm{~V}$. The ions were acquired in the $\mathrm{m} / \mathrm{z}$ range from 100 to 1000 with a scan rate of $3 \mathrm{scan} / \mathrm{s}$. The mass accuracy of MS scans was $<1 \mathrm{ppm}$. Targeted low-energy collision dissociation $\mathrm{MS} / \mathrm{MS}$ acquisitions were carried out at $50-1000 \mathrm{~m} / z$ with the scan rate of 3 scans per second for MS and 5 scans per second for MS/MS. The collision energies were set at 10, 20, and $40 \mathrm{eV}$ with nitrogen as the collision gas. Internal mass calibration was enabled, using two reference mass ions (121.0509 and 922.0098). The mass accuracy for MS scans was $<1 \mathrm{ppm}$. For MS/MS scans, the mass difference was $<5$ pm. Data analysis was carried out using Agilent Mass Hunter Qualitative software (version B.06). Accurate mass scan data were mined using the find by molecular feature (FMF), the find by formula (FbF), the find by targeted MS/MS, and molecular formula generator (MFG) algorithms. MassBank database (http://www.massbank. jp) was used to assist identification studies. 


\section{Results and Discussion}

\subsection{Thin-Layer Chromatography-Direct Bioautography}

The preliminary TLC-DB studies performed against B. subtilis proved the presence of many antibacterial components in the sage tincture in contrast to their lack in the $S$. officinalis EO [12]. The $S$. officinalis EO contains mainly non-polar, volatile terpenes without evident antibacterial properties. Thus, the main aim of this paper was to investigate the antibacterial properties of $S$. officinalis L. ethanol tincture against seven bacterial strains and to identify components possessing the widest range of antibacterial activity. The structural identification of the active compounds was carried out using LC-MS/MS analysis of fractions isolated from the TLC plates. Additionally, chemical derivatization of separated compounds with anisaldehyde-sulfuric acid reagent was performed. Preliminary TLC and TLC-DB studies were conducted to find the best separation conditions of the active tincture components. The selected mobile phase (chloroform-diethyl ether-methanol, 30:10:1, $v / v$ ) provided sufficient separation of the majority of compounds showing antibacterial activity.

Then, the plant tincture was applied on seven TLC plates which were developed with the chosen mobile phase and subjected to

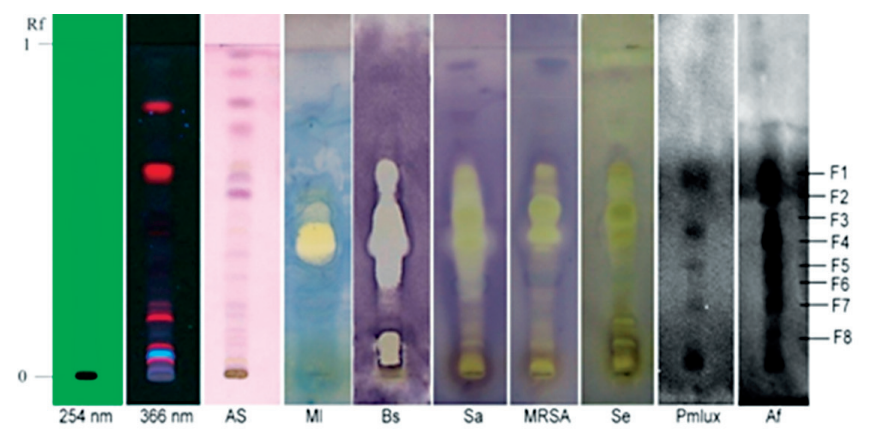

Figure 1

TLC chromatograms and bioautograms of $S$. officinalis $L$. tincture. F1-F8 bioactive fractions. AS derivatization with anisaldehydesulfuric acid reagent. Mobile phase: chloroform-diethyl ethermethanol $(30: 10: 1, v / v)$. bioautographic detection against all the seven tested bacterial strains. The bioautograms provided information on eight bioactive fractions denoted as F1-F8 (Figure 1). Semi-preparative TLC was used for isolation of these fractions. To obtain larger amounts of the fractions, $150 \mu \mathrm{L}$ of the extract as $15-\mathrm{cm}$ band was applied on an analytical TLC plate (see Section 2.2.3) and developed to a $8-\mathrm{cm}$ distance with the same mobile phase as used previously for analytical separation. Eight separated fractions, chosen using TLC-DB, were scraped off together with silica gel, and then each of them was eluted with $1 \mathrm{~mL}$ of methanol, evaporated to dryness, and then reconstituted to $200 \mu \mathrm{L}$ with pure methanol. The fractions $(15 \mu \mathrm{L})$ were reanalyzed by TLC-DB against Bs (one of the most sensitive bacterial strains) to confirm their activity (Figure 2). The same samples were subjected to LC-MS analyses.

\subsection{Liquid Chromatography-Mass Spectrometry}

To elucidate structures and to identify active compounds in fractions F1-F8, collision-induced dissociation (CID) of their molecular ions was performed and liquid chromatographyquadrupole time-of-flight (LC-Q-TOF) product ion spectra were acquired.

Table 1 lists masses of precursor ions $(\mathrm{m} / \mathrm{z})$, their retention times, generated formulas, measured and calculated monoisotopic masses as well as mass differences in parts per million (ppm). To obtain high-quality MS/MS data, rich in structural information, fragmentations were carried out at three collision energies: 10, 20, and $40 \mathrm{eV}$. The main fragment ions characteristic for the examined compounds are presented in Table 1.

The analysis of the first two fractions provided information about two compounds presented both in fractions F1 and F2. One of the protonated molecular ions was observed at $\mathrm{m} / \mathrm{z}$ 329.1024 for which molecular formula $\mathrm{C}_{18} \mathrm{H}_{16} \mathrm{O}_{6}$ was generated. The compound was tentatively identified as the flavonoid salvigenin. The fragmentation of this compound resulted in the presence of ions at $\mathrm{m} / \mathrm{z} 314.0802\left[\mathrm{M}-\mathrm{CH}_{3}\right]^{++}, 296.0679[\mathrm{M}-$ $\left.\mathrm{CH}_{3}-\mathrm{H}_{2} \mathrm{O}\right]^{++}$, and $268.0690\left[\mathrm{M}-\mathrm{CH}_{3}-\mathrm{H}_{2} \mathrm{O}-\mathrm{CO}\right]^{\cdot+}$.

The main component of fraction F4 forming the protonated molecular ion $[\mathrm{M}+\mathrm{H}]^{+}$at $\mathrm{m} / \mathrm{z} 315.0863$ and giving the molecular

A

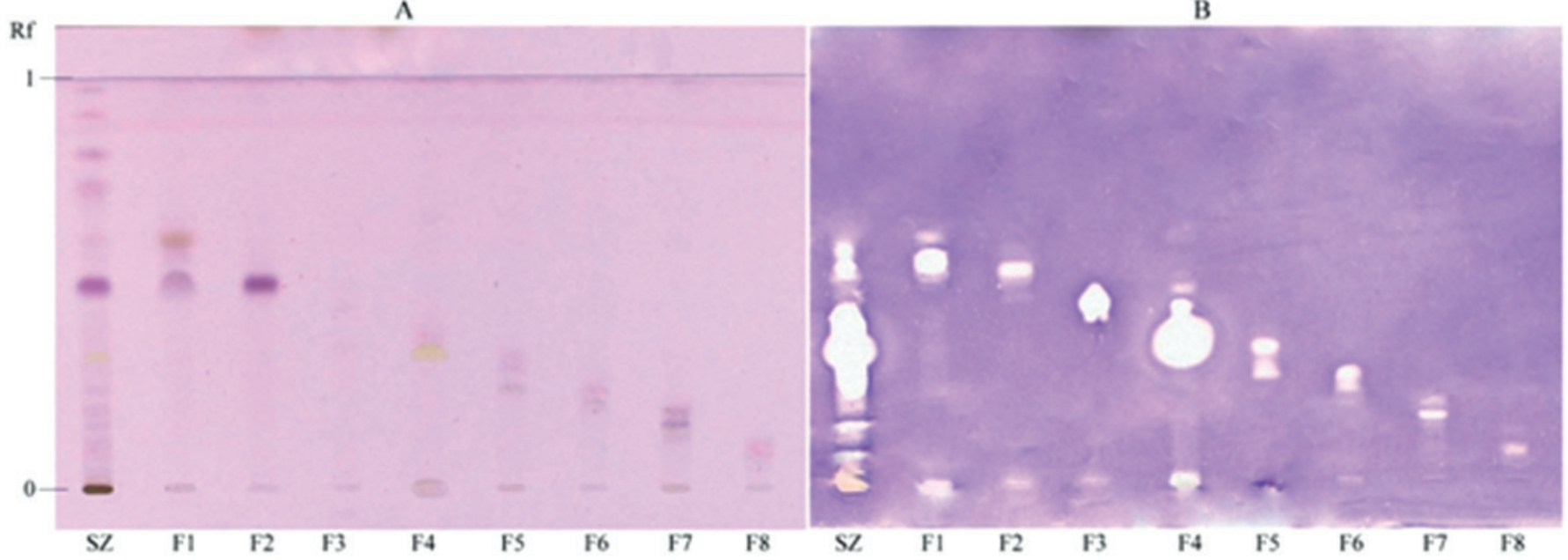

Figure 2

Chromatograms and bioautograms of S. officinalis L. extract (SZ) and isolated fractions F1-F8. Plates: (A) derivatization with AS reagent, (B) TLC-DB against B. subtilis. Mobile phase: chloroform-diethyl ether-methanol (30:10:1, v/v). 


\section{Table 1}

Compounds of fractions from S. officinalis L. identified by LC-MS/MS basing on structure elucidations and MassBank Database spectra comparison.

\begin{tabular}{|c|c|c|c|c|c|c|c|c|}
\hline \multirow{2}{*}{ Fraction } & \multirow{2}{*}{$t_{\mathrm{R}}$} & \multirow{2}{*}{$\begin{array}{l}m / z \\
{[\mathrm{M}+\mathrm{H}]^{+}}\end{array}$} & \multicolumn{2}{|c|}{ Monoisotopic mass } & \multirow{2}{*}{$\begin{array}{l}\text { Mass diff. } \\
{[\mathrm{ppm}]}\end{array}$} & \multirow{2}{*}{ Fragmentation ions } & \multirow{2}{*}{ Formula } & \multirow{2}{*}{ Compound } \\
\hline & & & Theoretical & Measured & & & & \\
\hline \multirow[b]{2}{*}{ F1 } & 8.015 & 329.1024 & 328.0947 & 328.0951 & -1.39 & $329.1028 ; 314.0802 ; 296.0679 ; 268.069$ & $\mathrm{C}_{18} \mathrm{H}_{16} \mathrm{O}_{6}$ & Salvigenin \\
\hline & 8.639 & 375.2168 & 374.2093 & 374.2096 & -0.66 & $\begin{array}{l}\text { 375.2164; 329.2101; 329.1744; 311.2001; } \\
\text { 301.1798; 283.169; 273.1849; 259.1326; } \\
\text { 251.1275; } 109.1011\end{array}$ & $\mathrm{C}_{22} \mathrm{H}_{30} \mathrm{O}_{5}$ & - \\
\hline \multirow{2}{*}{$\mathrm{F} 2$} & 8.027 & 329.1016 & 328.0947 & 328.0944 & 0.86 & $\begin{array}{l}329.1009 ; 314.0791 ; 296.0686 ; 268.0725 \\
213.0539 ; 159.1164\end{array}$ & $\mathrm{C}_{18} \mathrm{H}_{16} \mathrm{O}_{6}$ & Salvigenin \\
\hline & 8.631 & 375.2167 & 374.2093 & 374.2093 & 0.14 & $\begin{array}{l}375.2155 ; 329.2098 ; 301.179 ; 273.1844 \\
109.1006\end{array}$ & $\mathrm{C}_{22} \mathrm{H}_{30} \mathrm{O}_{5}$ & - \\
\hline F3 & 8.319 & 405.1906 & 404.1835 & 404.1835 & 0.05 & $\begin{array}{l}331.154 ; 303.1591 ; 285.1487 ; 275.1636 \\
273.1482 ; 261.112 ; 247.0961\end{array}$ & $\mathrm{C}_{22} \mathrm{H}_{28} \mathrm{O}_{7}$ & - \\
\hline F4 & 6.903 & 315.0863 & 314.079 & 314.079 & 0.01 & $\begin{array}{l}315.0865 ; 300.062 ; 282.0527 ; 254.0566 ; \\
226.0617 ; 136.0143\end{array}$ & $\mathrm{C}_{17} \mathrm{H}_{14} \mathrm{O}_{6}$ & Cirsimaritin \\
\hline \multirow{2}{*}{ F5 } & 6.825 & 347.1856 & 346.178 & 346.1783 & -0.75 & $\begin{array}{l}347.1842 ; 301.179 ; 283.1686 ; 273.1845 ; \\
241.1219 ; 231.1011\end{array}$ & $\mathrm{C}_{20} \mathrm{H}_{26} \mathrm{O}_{5}$ & Rosmanol \\
\hline & 9.308 & 347.2215 & 346.2144 & 346.2143 & 0.26 & $\begin{array}{l}347.1844 ; 301.2161 ; 231.137 ; 219.1379 \\
205.1221\end{array}$ & $\mathrm{C}_{21} \mathrm{H}_{30} \mathrm{O}_{4}$ & $\begin{array}{l}12 \text { - } O \text {-methyl } \\
\text { carnosic acid }\end{array}$ \\
\hline \multirow{2}{*}{ F6 } & 6.823 & 347.1856 & 346.178 & 346.1784 & -1.21 & $\begin{array}{l}347.182 ; 301.1794 ; 283.1678 ; 273.1838 \\
259.132 ; 241.1228 ; 231.1014 ; 109.1016\end{array}$ & $\mathrm{C}_{20} \mathrm{H}_{26} \mathrm{O}_{5}$ & Rosmanol \\
\hline & 7.957 & 333.2063 & 332.1988 & 332.199 & -0.61 & $\begin{array}{l}333.2064 ; 315.1569 ; 301.1767 ; 273.1828 \\
217.121 ; 207.141 ; 159.1207\end{array}$ & $\mathrm{C}_{20} \mathrm{H}_{28} \mathrm{O}_{4}$ & Carnosic acid \\
\hline \multirow{2}{*}{ F7 } & 7.574 & 483.2226 & 482.2152 & 482.2155 & -0.58 & $\begin{array}{l}\text { 483.2219; 455.1902; 437.2168; 409.184; } \\
367.175 ; 339.1435 ; 335.1491 ; 265.1065\end{array}$ & $\mathrm{C}_{24} \mathrm{H}_{34} \mathrm{O}_{10}$ & - \\
\hline & 8.056 & 317.2690 & 316.2614 & 316.2616 & -0.8 & $\begin{array}{l}\text { 307.2693; 299.2584; } 235.2055 \\
\text { 217.195; 161.1319; }\end{array}$ & $\mathrm{C}_{18} \mathrm{H}_{36} \mathrm{O}_{4}$ & - \\
\hline F8 & 7.566 & 313.2372 & 312.2301 & 312.2298 & 0.98 & $\begin{array}{l}313.2353 ; 277.216 ; 259.2049 ; 147.1172 \\
141.1266 ; 137.0959\end{array}$ & $\mathrm{C}_{18} \mathrm{H}_{32} \mathrm{O}_{4}$ & - \\
\hline
\end{tabular}

formula $\mathrm{C}_{17} \mathrm{H}_{14} \mathrm{O}_{6}$ has been tentatively identified as cirsimaritin. As a result of the cleavage of one of two methyl groups linked to the ring A, the ion $m / z 300,062\left[\mathrm{M}-\mathrm{CH}_{3}\right]^{\circ+}$ was obtained which during further fragmentation was disintegrated to ion $\mathrm{m} / \mathrm{z} 282.0522\left[\mathrm{M}-\mathrm{CH}_{3}-\mathrm{H}_{2} \mathrm{O}\right]^{++}$. The loss of one and two carbon monoxide molecules led to the formation of ions at $\mathrm{m} / \mathrm{z} 254.0566$ $\left[\mathrm{M}-\mathrm{CH}_{3}-\mathrm{H}_{2} \mathrm{O}-\mathrm{CO}\right]^{++}$and $m / z 226.0617\left[\mathrm{M}-\mathrm{CH}_{3}-\mathrm{H}_{2} \mathrm{O}-2 \mathrm{CO}\right]^{*+}$.

The components identified in fractions F5 and F6 were di- and triterpenes typical for plants from the Lamiaceae family. In fraction $\mathrm{F} 5$, the presence of $12-O$-methyl carnosic acid was confirmed (protonated molecular ion at $\mathrm{m} / \mathrm{z} 347.2215$ and molecular formula $\left.\mathrm{C}_{21} \mathrm{H}_{30} \mathrm{O}_{4}\right)$ as well as of rosmanol $(\mathrm{m} / z 347.1856$ and $\mathrm{C}_{20} \mathrm{H}_{26} \mathrm{O}_{5}$, respectively) which was present also in F6, together with carnosic acid $\left(\mathrm{m} / \mathrm{z} 333.2063\right.$ and $\mathrm{C}_{20} \mathrm{H}_{28} \mathrm{O}_{4}$, respectively). For all these compounds, the cleavage of water and carbon monoxide molecules during fragmentation is observed. In the case of rosmanol and carnosic acid, common ion at $\mathrm{m} / \mathrm{z}$ $301.1794\left(\mathrm{C}_{19} \mathrm{H}_{25} \mathrm{O}_{3}^{+}\right)$was detected which, by further decarboxylation, gives ion at $m / z 273.1838\left(\mathrm{C}_{18} \mathrm{H}_{25} \mathrm{O}_{2}^{+}\right)$. For these three compounds, the loss of mass 116.0837 is characteristic. It can be attributed to the cleavage of molecules pentene, water, and carbon monoxide which leads to the formation of the ions at $\mathrm{m} / \mathrm{z}$
231.1014 $\left(\mathrm{C}_{14} \mathrm{H}_{15} \mathrm{O}_{3}^{+}\right)$for rosmanol, $217.1210\left(\mathrm{C}_{14} \mathrm{H}_{17} \mathrm{O}_{2}^{+}\right)$for carnosic acid, and $231.1370\left(\mathrm{C}_{15} \mathrm{H}_{19} \mathrm{O}_{2}^{+}\right)$for 12-O-methyl carnosic acid. For two characteristic ions at $\mathrm{m} / z 219.1379$ and 205.1221 present in the spectrum of 12-O-methyl carnosic acid, the formulas $\mathrm{C}_{14} \mathrm{H}_{19} \mathrm{O}_{2}^{+}$and $\mathrm{C}_{13} \mathrm{H}_{17} \mathrm{O}_{2}^{+}$, respectively were determined. However, these compounds were not identified.

The LC-Q-TOF product spectra of the components of fractions F1, F2, and F4-F6 are presented in Figure 3.

The compounds detected as the main components of fractions F3, F7, and F8 were not identified.

\section{Conclusion}

TLC-DB is a very useful and not expensive tool for guiding the isolation and identification of biologically active compounds on the TLC plate. The antibacterial components of $S$. officinalis L. extract, active against seven bacterial strain, were identified by effect-directed analysis combining TLC-DB and subsequent LC-MS/MS analysis of zones interested. The extract was tested against seven bacteria: $M$. luteus, B. subtilis, 
S. aureus, MRSA, S. epidermidis, P. syringae pv. maculicola, and $A$. fischeri. Eight fractions with the widest antimicrobial spectrum were detected and isolated using TLC-DB followed by semi-preparative TLC. Five bioactive components were further tentatively identified by $\mathrm{LC}-\mathrm{MS} / \mathrm{MS}$ as salvigenin, cirsimaritin, rosmanol, carnosic acid, and 12-O-methyl carnosic acid. All of them contribute to the strong biological properties of S. officinalis [1-3]. Diterpenes, like rosmanol, carnosic acid,
F1

F2

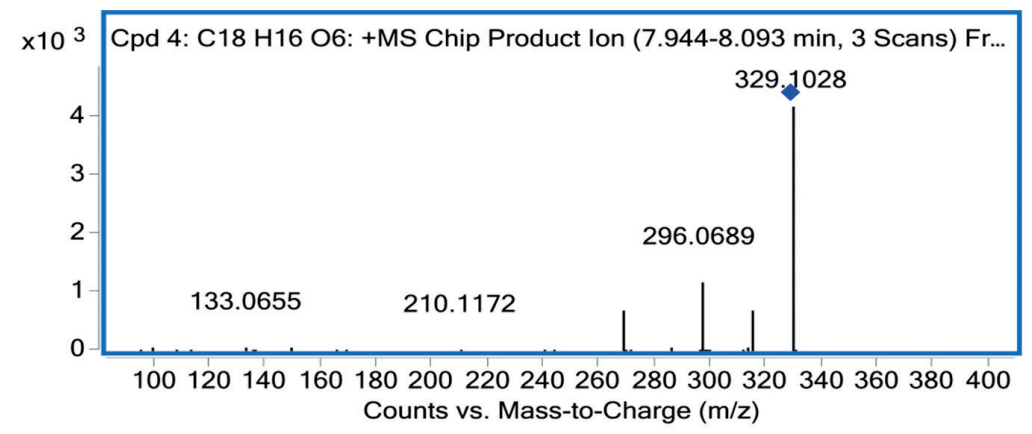

F4

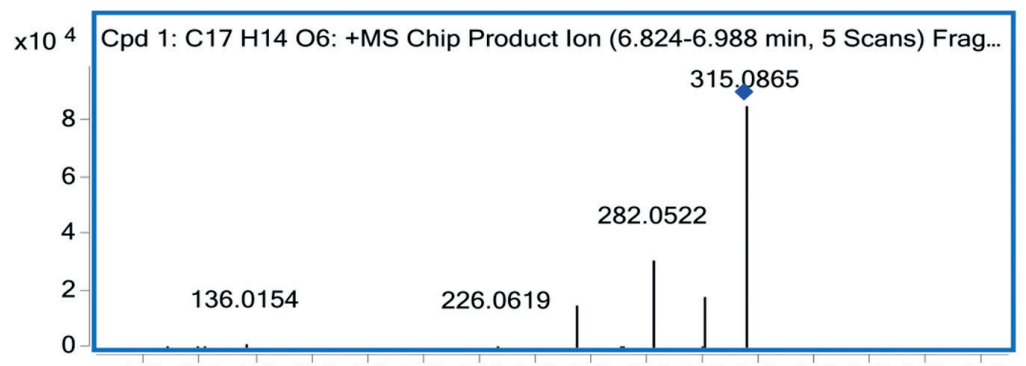

100120140160180200220240260280300320340360380400 Counts vs. Mass-to-Charge ( $\mathrm{m} / \mathrm{z})$

F5

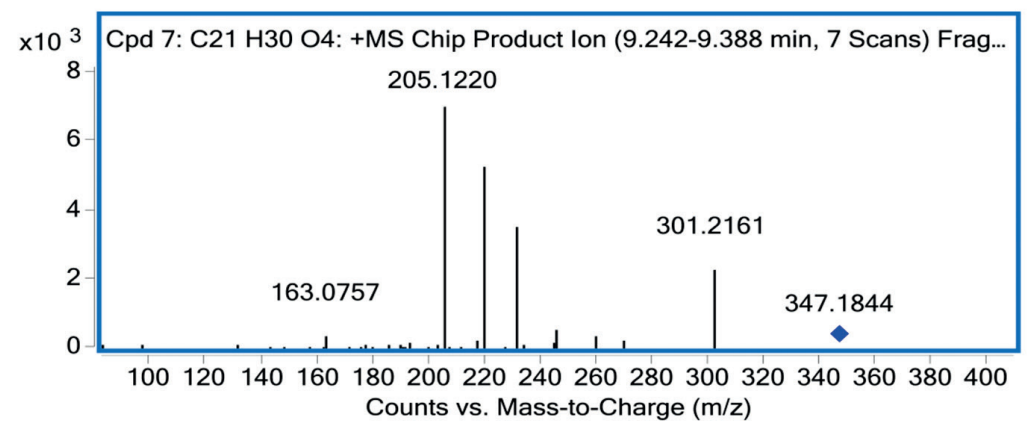

F5

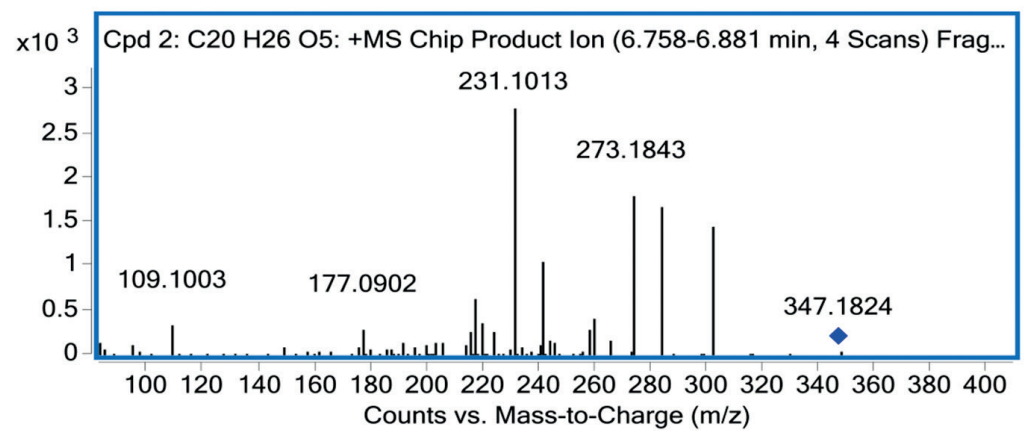

F6

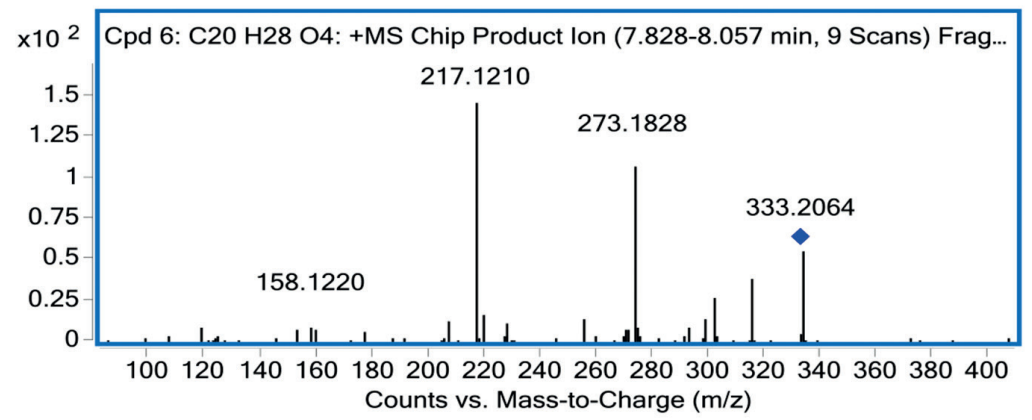<smiles>COc1ccc(-c2cc(=O)c3c(O)c(OC)c(OC)cc3o2)cc1</smiles>

salvigenin<smiles>COc1cc2oc(-c3ccc(O)cc3)cc(=O)c2c(O)c1OC</smiles>

cirsimaritin<smiles>COc1c(C(C)C)cc2c(c1O)[C@]1(C(=O)CCCC1(C)C)[C@@H]1CCCC21C</smiles>

12-O-methyl carnosic acid

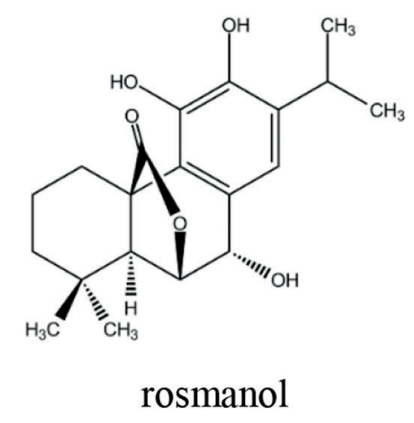<smiles>CC(C)c1cc2c(c(O)c1O)[C@@]1(O)CCCC(C)(C)[C@H]1CC2</smiles>

carnosic acid

Figure 3

LC-Q-TOF product spectra of components of fractions F1, F2, and F4-F6; collision energy, $20 \mathrm{eV}$. 
and its derivatives, are responsible for the antibacterial activity (confirmed in this study) as well as for the strong antioxidant properties of the sage extract which is used in food industry as a natural antioxidant [13]. Flavonoids, like salvigenin and cirsimaritin, have antioxidant, analgesic, and anti-inflammatory properties $[13,14]$.

\section{Acknowledgments}

We gratefully thank Dr. hab. Emilia Fornal for the use of the MS services and facilities of the Center for Interdisciplinary Research of The John Paul II Catholic University of Lublin, Poland, funded by POPW.01.03.00-06-003/09-00. We are grateful to Herbapol-Lublin S.A. for delivering to us the ethanol plant extract. This work was partially supported by the Hungarian Scientific Research Fund (OTKA) grant PD83487. Ágnes M. Móricz was supported by a Bolyai grant.

\section{Open Access Statement}

This is an open-access article distributed under the terms of the Creative Commons Attribution-NonCommercial 4.0 International License (https://creativecommons.org/licenses/by-nc/4.0/), which permits unrestricted use, distribution, and reproduction in any medium for non-commercial purposes, provided the original author and source are credited, a link to the CC License is provided, and changes - if any - are indicated.

\section{References}

[1] S.E. Kintzios, Sage: The Genus Salvia, CRC Press, Boca Raton, FL, 2000.

[2] W.C. Evans, Pharmacognosy, Saunders, London, 2000.
[3] N. Adrar, N. Oukil, F. Bedjou, Ind. Crops Prod. 88 (2016) 112-119.

[4] I.M. Choma, E.M. Grzelak, J. Chromatogr. A 1218 (2011) 2684-2691.

[5] A. Marston, J. Chromatogr. A 1218 (2011) 2676-2683.

[6] M. Waksmundzka-Hajnos, M. A. Hawryt, Ł. Cieśla, in: C.F. Poole (ed.), Instrumental Thin-Layer Chromatography; Chapter 19, Elsevier, Amsterdam, 2015, pp. 505-553.

[7] I.M. Choma, W. Jesionek, Effect-Directed Detection in Chromatography, Reference module in Chemistry, Molecular Sciences and Chemical Engineering, Elsevier, Amsterdam, 2017.

[8] Á.M. Móricz, P.G. Ott, in: E. Tyihák (ed.), Forced-Flow Layer Chromatography, Chapter 6, Elsevier, Amsterdam, 2016, pp. 347-395.

[9] I.M. Choma, W. Jesionek, in: C.F. Poole (ed.), Instrumental Thin-Layer Chromatography, Chapter 11, Elsevier, Amsterdam, 2015, pp. 279-312.

[10] G. Morlock, in: G.K. Jayprakasha, B.S. Patil, F. Pellati (eds.), Instrumental Methods for the Analysis and Identification of Bioactive Molecules, Chapter 5, ACS Symposium Series, vol. 1185, American Chemical Society, Washington, DC, 2014, pp. 101-121.

[11] H. Wagner, S. Bladt, Plant Drug Analysis: A Thin Layer Chromatography Atlas, 2nd edn., Springer, Munich, 2001.

[12] W. Jesionek, B. Majer-Dziedzic, I.M. Choma, J. Liq. Chromatogr. Relat. Technol. 40 (2017) 292-296.

[13] A. Ghorbani, M. Esmaeilizadeh, J. Tradit. Complementary Med. (2017); http://dx.doi.org/10.1016/j.tcme.2016.12.014.

[14] A.H. Mansourabadi, H.M. Sadeghi, N. Razavi, E. Rezvani, Adv. Herb. Med. 1 (2015) 31-41.

Ms received: May 18, 2017 Accepted: July 3, 2017 